\title{
FILOSOFIA, PSICOLOGIA E PSICANÁLISE: A INFÂNCIA EM WALTER BENJAMIN E GASTON BACHELARD
}

\author{
PHILOSOPHY, PSYCHOLOGY AND PSYCHOANALYSIS: CHILDHOOD BY WALTER \\ BENJAMIN AND GASTON BACHELARD
}

\author{
Henrique Gianotti ${ }^{1}$ \\ PPGSSE - Universidade São Francisco - USF \\ Bolsista de Iniciação Científica CNPq
}

Luzia Batista de Oliveira Silva²

Docente PPGSSE - USF

\begin{abstract}
RESUMO: Este artigo apresenta o resultado de um projeto de iniciação científica intitulado Filosofia, Psicologia e Psicanálise: Poéticas da Infância e da Educação, vinculado à linha de pesquisa Educação, Sociedade e Processos Formativos do PPGSS em Educação, da Universidade São Francisco-USF sob orientação da Prof ${ }^{a}$. Dra. Luzia Batista de Oliveira Silva. Investigaram-se, através de leituras, as obras de Walter Benjamin e Gaston Bachelard que têm como fio condutor uma descrição poética da infância, cujo tema trabalhado correlaciona-se com as teorias da Psicanálise e da Psicologia Analítica desenvolvidas por Sigmund Freud e Carl Gustav Jung, respectivamente, os quais tiveram obras analisadas posteriormente. Partiu-se da ideia de que ambos os filósofos, delinearam imagens poéticas, estéticas e filosóficas, relevantes na compreensão da percepção e da cognição da criança. Entende-se que mesmo na atualidade, os autores, tanto da filosofia quanto da psicologia são pouco explorados no processo educacional, o que, de certa forma, sinaliza que é possível avançar para oferecer uma nova perspectiva para se pensar o mundo e a educação. Baseadas nisso, a Psicologia e a Psicanálise aparecem como aliadas da Educação, oferecendo olhares específicos sobre a cognição, a percepção e os aspectos emocionais do aluno, seguindo o modelo biopsicossocial. Foi possível identificar, nas noções de infância e educação dos autores, contribuições para processos educacionais futuros e novas visões a respeito da infância.
\end{abstract}

Palavras-chave: Educação, Psicologia, Infância, Walter Benjamin, Gaston Bachelard.

\footnotetext{
${ }^{1}$ Graduando do Curso de Psicologia da Universidade São Francisco - USF e pesquisador de Iniciação Científica, pelo PPGSSE - Programa de Pós-Graduação Stricto Sensu em Educação da USF - Itatiba. Membro pesquisador do Grupo de Pesquisa TCTCLAE - Teoria Crítica e Teorias Críticas Latino-Americanas e Educação. Bolsista PIBIC do CNPQ (2018-2019 - relatório final com menção honrosa) e (2019-2020).

${ }^{2}$ Luzia Batista de Oliveira Silva - Docente no Programa de Pós-Graduação Stricto Sensu em Educação PPGSSE/USF; é Bacharel e Mestre em Filosofia pela PUC/SP, Doutora em Educação pela FE/USP, possui pósdoutorado em Antropologia/Ciências Sociais pela PUC/SP e pós-doutorado em Filosofia pela UnB - Universidade de Borgonha, Dijon/FR. Líder dos Grupos de Pesquisa TCTCLAE - Teoria Crítica e Teorias Críticas LatinoAmericanas e Educação - CNPq/USF; Estética, Educação Superior e Infầncia - CNPq/USF.
} 
ABSTRACT - This article presentes the result of a Science Iniciation project entitled Philosophy, Psychology and Psychoanalysis: Childhood and Education Poetics, linked to the research line Education, Society and Formative Processes from the Graduate Program in Education of Universidade São Francisco - USF under the orientation of Luzia Batista de Oliveira Silva, PhD. The works of Walter Benjamin and Gaston Bachelard that has as its guiding thread a poetic description of childhood were investigated through reading, whose worked theme correlates with the theories of Psychoanalysis and Analytical Psychology developed, respectively, by Sigmund Freud and Carl Gustav Jung, who had their works analyzed later. It was assumed that both philosophers Walter Benjamin and Gaston Bachelard developed poetic, aesthetic and philosophical images, relevant to the understanding of the child's perception and cognition. It is understood that even today, the authors of both philosophy and psychology are little explored in the educational process, which, in a way, signals that it is possible to move forward to offer a new perspective of thinking the world and the education. Based on this, Psychology and Psychoanalysis appears as allies in Education, offering specific views on the student's cognition, perception and emotional aspects, following the biopsychosocial model. It was possible to identify in the childhood and education concepts of the authors contributions to further educational processes and new views about the childhood.

Key words: Education, Psychology, Childhood, Walter Benjamin, Gaston Bachelard.

\section{INTRODUÇÃO}

O processo educacional torna o indivíduo consciente a respeito de si mesmo e do seu papel no mundo, deixando o seu papel de ser subjetivo e passando a ser objetivo de si mesmo (ABBAGNANO, 2007), ou seja, a educação, por tratar-se de um processo complexo, precisa ser tema pertinente de pesquisas e do desenvolvimento constante de novas teorias a fim de renovar as diretrizes de algo que proporciona aos sujeitos uma possibilidade de mudança.

A definição de educação no Dicionário Breve da Pedagogia (2000) é clara quanto ao papel da educação que "designa o processo de desenvolvimento e realização do potencial intelectual, físico, espiritual, estético e afetivo existente em cada criança" (MARQUES, 2000, p 36) deixa claro que o papel da educação é desenvolver algo que já existe na criança, apoiando-a para traçar o seu próprio caminho.

A Psicologia, oferecendo um olhar focado nos processos cognitivos, emocionais e perceptuais do aluno, pode ser uma aliada da Educação. Utilizando-se de múltiplos saberes para obter melhores desempenhos dos alunos e avançar, cada vez mais, no que diz respeito às formas de lidar com as dificuldades do processo ensino e aprendizagem, essa ciência apresenta conceitos que podem ser incorporados ao processo educacional. (MARTINEZ, 2010).

Walter Benjamin (1892-1940) foi um filósofo que se ocupou da infância e da criança como um ponto de partida importante para seus pensamentos e reflexões. Ele apresenta uma perspectiva diferenciada sobre a infância, valorizando as experiências, fazendo uma denúncia no que se refere ao pessimismo moderno do olhar do adulto voltado para a criança (SANTOS, 2015). 
Gaston Bachelard escreveu sobre a existência da objetividade material e a dinâmica do conhecimento estético-poético de mundo, valorizando, assim, a infância em variados escritos, afirmando que as imagens e a imaginação da criança são elementos importantes para o desenvolvimento de conhecimentos. A criança tem capacidade para criar novos olhares sobre a vida e a sua infância, dado que ela está, constantemente, explorando e investigando o mundo através de novas sensações e do ato de brincar (RICHTER, 2002).

Partiu-se do projeto Walter Benjamin e Gaston Bachelard: aproximaçoes sobre a infância e a educação da Profa. Dra. Luzia Batista de Oliveira Silva como inspiração, desenvolveu-se um projeto de iniciação científica que buscou analisar, nas obras de Benjamin e Bachelard, algumas imagens estético-poéticas da infância e da educação. Partiu-se da hipótese de que tanto Benjamin quanto Bachelard tiveram influência de Sigmund Freud e Carl Jung e enxergaram, em suas reflexões e críticas filosóficas, elementos relevantes para a formulação de uma poética da infância no que tange à dimensão da ética e estética. O objetivo do projeto foi correlacionar os olhares desses autores para reconfigurar alguns conceitos utilizados na Educação e proporcionar possíveis mudanças que possam enriquecer o processo.

\section{MÉTODO}

Trata-se de uma pesquisa bibliográfica das obras dos filósofos que retratam a infância, pautar-se por procedimentos metodológicos e uma metodologia reflexiva sobre os olhares estéticopoéticos dos filósofos em questão e estabelecendo, com isso, relação e convergência de olhares com obras de Psicologia, de Freud e Jung.

\section{RESULTADOS E DISCUSSÃO}

Walter Benjamin oferece uma perspectiva da criança como um ser livre, não contaminado pela experiência e a frustração da vida adulta, que enxerga os detalhes do mundo e tem a imaginação livre para ser tudo e fazer qualquer coisa ganhar vida e forma. Em Reflexões sobre a criança, o brinquedo, a educação, Benjamin traz uma série de textos reflexivos, dentre eles, Experiência, um ensaio onde o autor nos explica que "a máscara do adulto chama-se 'experiência'. Ela é inexpressiva, impenetrável, é o sempre igual" (BENJAMIN, 2002, p 21). O autor descreve como o adulto e sua experiência de vida tendem a diminuir a experiência do jovem. O adulto vê no jovem seus sonhos de juventude quebrados e, assim, busca retaliá-lo, algo que, provavelmente, se desenvolve devido ao sentimento de culpa e censura que lhe foi inculcado na infância. Em $A$ hora das crianças, nos relatos da sua própria infância para um programa de rádio, o ensaísta deixa claro, mais uma vez, o valor do olhar 
imaginativo de uma criança sobre o mundo, e como isso deve ser valorizado no caminho que essa criança for seguir, e não retaliado, já que “as coisas que mais dão certo são aquelas que amávamos e planejávamos desde mais cedo" (BENJAMIN, 2015, p. 54).

Ao mesmo tempo em que denuncia a experiência da criança sendo contaminada pela visão do adulto, em Experiência e Pobreza, Benjamin afirma que, apesar de fundamental, os seres humanos têm dado pouco valor à experiência, e não a absorvem e a transmitem mais como antes. Vivem somente para o agora e, assim, formam uma barbárie que terá como resultado o enfraquecimento cultural. O homem atual vive pelo trabalho e pelo capital; ele não é ignorante, apenas está exausto de tudo que consome, revelando por isso, sua pobreza interna e externa.

Benjamin também discute em seus textos, numa visão marxista, como a luta de classes influencia o processo educacional. No ensaio Uma Pedagogia Comunista, o filósofo destaca o caráter inconsciente da educação de acordo com a classe social na qual a criança está inserida. A burguesia enxerga suas crianças como herdeiras de uma cultura superior não busca novos saberes, mas tão somente status quo - legado de privilégios da família, enquanto a classe proletária vê as suas crianças como os futuros auxiliares num processo de mudança e transformação social buscando sempre novos e melhores saberes, porque são os que lutarão por essas mudanças e transformações sociais e humanas. Talvez, quem sabe, possam contribuir para mudar o curso da história dos vencidos sociais e, assim, participar da construção de uma nova história.

Benjamin defende que a criança deve ser educada como o adulto em relação à luta das classes sociais, já que a elas pertence e existe. A educação deve ter um quê de rebeldia para ser, de fato, revolucionária, o que implica dizer que é necessário educar para que ela tenha consciência de sua classe social e dos valores que ela detém. "Benjamin traz valorização da cultura popular e do cidadão comum, levando o ouvinte a perceber a importância da informação e da cultura que cada pessoa possui sem ter a percepção da gama de informações que domina” (GALVÃO; SILVA, 2016).

Gaston Bachelard, o segundo autor objeto desta pesquisa, analisa, de forma estético-poética, os devaneios e os espaços onde os seres humanos podem dar sentido à sua existência. Em A poética do devaneio, Bachelard (1996) explora o conceito de devaneio e a contribuição da fenomenologia para análise desse conceito. Ele faz uma crítica à Psicologia e à Psicanálise que desconsideram o devaneio, trabalhando essencialmente com o material consciente diurno e o inconsciente dos sonhos, assim como critica o conceito de sexualidade, primordialmente a infantil, como tão importantes nessas teorias. Diz que o devaneio tem um material muito rico para a análise, que é feita pela fenomenologia.

Para Bachelard, diferentemente do sonho noturno cheio de elementos estranhos que confundem a alma, o devaneio, de origem inconsciente, não necessita do sonho noturno, é uma 
viagem de olhos abertos, uma viagem que liberta, conforta e repousa a consciência cansada, entediada; é o saber desligar-se da luta cotidiana e sem trégua num mundo em que o capital dita regras e comportamentos. Entender esse devaneio, o sonho acordado, nos faz recarregar as energias e querer ser livre das amarras que nos prendem, como fazem os poetas. Contudo, o autor não foca, especificamente, no sujeito que escreve e nem se baseia em suas histórias de vida, mas naquilo que está subjacente nos escritos poéticos, nas histórias no tocante à essência das palavras, àquilo que é escrito e como é escrito pelos poetas e escritores.

Falando especialmente sobre a criança, Bachelard descreve o devaneio infantil, que conhece uma existência sem limites e, portanto, deve ser muito valorizado: "seu devaneio não era simplesmente um devaneio de fuga. Era um devaneio de alçar voo" (BACHELARD, 1996, p. 94). Ele também defende que as imagens da infância permaneçam em nós por ser o que permite nossa abertura para as coisas novas; é o que nos permite amar as crianças e a figura simbólica que elas representam para o adulto. "A infância permanece em nós como um princípio de vida profunda, de vida sempre relacionada à possibilidade de recomeçar" (BACHELARD, 1996, p. 119). É justamente essa criança que permanece em nós e que é responsável pelo nosso amor, pelos sonhos, pelos atos bons.

Numa visão semelhante à de Benjamin, Bachelard aponta como a criança é forçada a seguir o caminho dos adultos, tornando-se um homem prematuro, um "adulto em miniatura" como bem denunciou Rousseau, o que significa que terá este adulto recalcada sua infância. Ele ainda descreve como a criança vê o mundo de forma ingênua, verdadeira, em cores primeiras. Os adultos tendem a tomar as crianças como tolas, ingênuas, sonhadoras, distantes da realidade, mas, na verdade, são elas que enxergam o mundo como ele é na realidade, justamente porque a infância é sem complexos, sem energias psíquicas neuróticas. Bachelard usa de termos junguianos a todo momento nas suas obras, como arquétipos, complexos, animus e anima mostrando a relação deles com a Psicologia Analítica.

Certamente, é esse tipo de apreciação fenológica atravessada pela psicologia junguiana e freudiana que ele, na obra $A$ poética do espaço, discute a poética por trás da figura da casa e dos espaços, lamentando como o adulto se prende aos bens materiais envolvidos numa casa e, por isso, perde a noção geral da figura que a casa representa para a criança e sua infância. Para a criança, a casa representa uma figura muito importante, especialmente a casa natal, que permanece na lembrança do adulto por toda a vida por meio dos poderes do inconsciente, posto que "A infância é maior que a realidade" (BACHELARD, 1974, p 207). A imaginação e o sonho da criança transformam o espaço, algo também descrito em $O$ direito de sonhar, onde o autor também salienta 
a importância da imaginação e dos sonhos para modificarmos o mundo em que vivemos, dando, mais uma vez, destaque à criança que permanece em nós como a responsável por esses sonhos.

A respeito da Pedagogia, Bachelard propõe a chamada "Pedagogia do Não" ou "Pedagogia do Contra", como Georges Jean (1989) a nomeia. Isso não quer dizer que ele seja contra a pedagogia, a escola ou os professores, e, sim, que ele propõe uma forma de pedagogia que vai contra muitas regras que são seguidas. Bachelard é contra verdades absolutas, explicações únicas sobre as coisas e a imposição disso às crianças. É preciso, deixá-las usar a imaginação, equilibrandoa com a razão, deixá-las desenvolver seu próprio saber, sendo contra as experiências imediatas. Ele é contra a visão "superior" dos adultos (professores e pais) sobre as crianças, visto que, na verdade, o mundo adulto, além de não ser superior, ainda destrói a poesia da infância. Deve-se ainda valorizar o erro e o fracasso e não os desprezar. Ele é contra os professores se manterem aferrados em certos saberes, devendo sempre se reinventar. "Não se conformar nunca com os 'dados imediatos' dos sentidos. Não pensar nunca que a pedagogia é a arte de vulgarizar os conhecimentos ou as práticas para fazê-las mais facilmente assimiláveis” (JEAN, 1989, p127 tradução nossa). Outra visão um tanto controversa do autor é ser contra as apostilas, livros e manuais de educação, pois, segundo ele, “certas forma de memória, como os manuais, 'imobilizam' o pensamento racional.” (JEAN, 1989, p 152 tradução nossa).

Após a análise das principais obras poéticas de Benjamin e Bachelard sobre a infância, o passo seguinte foi aproximar-nos da visão que eles têm da Psicologia e a Psicanálise, presente nas obras de Sigmund Freud e Carl Jung.

Freud, o pai da Psicanálise e o pioneiro no trabalho com o inconsciente, revolucionou a visão de infância ao propor que toda criança é dotada de sexualidade, desde o seu nascimento. Não se trata da sexualidade objetificada no ato sexual, como muitos acreditam, mas, sim, como representação de sentimentos, afetos e prazeres. A principal obra analisada de Freud foi $O$ MalEstar da Civilização, uma obra de caráter sociológico do psicanalista. Nela, Freud cita as diferentes formas com as quais o ser humano tenta se livrar do sofrimento discutindo também a questão do sentimento de culpa instituído na sociedade, fazendo críticas ao modelo religioso, sentimental e comportamental dos indivíduos. "O preço do progresso cultural é a perda da felicidade, pelo acréscimo do sentimento de culpa" (FREUD, 2010, p 106). No caso da criança, o sentimento de culpa nasce a partir da atividade dos pais (o medo da autoridade) e, posteriormente, pela sociedade, até a formação do superego, segunda fonte da culpa, dessa vez, internalizada, de um sujeito. "O Eu da criança tem que se contentar com o triste papel da autoridade assim degradada - o pai" (FREUD, 2010, p 100). 
Jung, fundador da Psicologia Analítica, antes fora um discípulo do próprio Freud, mas acabou rompendo com a Psicanálise original por divergências teóricas. Jung adaptou o conceito da libido de Freud, uma energia psíquica voltada às realizações do nosso instinto sexual, teorizando que ela é uma energia que vai além do sexual; é uma energia de vida que promove evolução. Além disso, ele também descreveu a possibilidade de indivíduos serem introvertidos, ou seja, as questões psicológicas podem estar voltadas ao eu (ego), e se são extrovertidos, as questões psicológicas estão voltadas para as relações objetais, que é a única forma como Freud trabalha para compreender essas questões. A principal inovação no trabalho de Jung diz respeito ao conceito de inconsciente coletivo, o que não significa desacreditar no inconsciente individual de Freud. Para Jung, existe uma parte do inconsciente que reside numa área mais profunda da psique, de origem ancestral, e que pode guiar todos os seres humanos, independentemente das experiências individuais. É nessa parte do inconsciente que, de acordo com Jung, se formam os arquétipos. (FILLOUX, 1966).

Para Jung, a criança é um ser que muito tem a oferecer com os seus pensamentos e formas de ver o mundo para os adultos, mas, quando reprimida pelos adultos, pode acontecer que a subestimemos, e "Por uma criança ser fisicamente pequena e seus pensamentos conscientes poucos e simples, não avaliamos as extensas complicações da sua mente infantil”' (JUNG, 1977, p. 99). Em O Homem a descoberta de sua alma, Jung discute o quanto as crianças já possuem seus desejos e destinos bem trilhados pelas suas almas e o quanto isso é difícil de ser compreendido pelos adultos: “em cada criança preexiste uma disposição psíquica funcional, adequada anterior a consciência" (JUNG, 1975, p 60). Isso explica os ataques, as teimosias, a timidez e o recolhimento que a criança mostra, pois esses chamados são persistentes e não querem colocar a criança contra o mundo, mas, sim, protegê-la: "De repente, a troco de nada, a criança mostra quem ela é, o que precisa fazer" (HILLMAN, 1997, p 23). Enquanto Walter Benjamin, filósofo da análise do nosso projeto, se aproxima de Freud em seus escritos, Bachelard se afasta. Segundo Filloux (1966), a crítica de Bachelard à Psicanálise se dá pelo fato de o filósofo considerar que a Psicanálise freudiana se prende, excessiva e unicamente, ao passado do autor e aos sintomas que levam à neurose, trabalhando de uma forma médica, focando somente no indivíduo. Nas obras de Bachelard, podemos ver que ele considera outros elementos na análise do inconsciente, como, por exemplo, os quatro elementos da natureza. Nesse sentido, Bachelard se aproxima mais de Jung, com sua visão mais holística, considerando arquétipos e complexos e a presença de uma infância permanente nos indivíduos e a própria teoria de animus e anima, citada em $A$ poética do devaneio. 


\section{CONCLUSÃO}

A partir das obras estudadas e analisadas, foi possível compreender como Walter Benjamin e Gaston Bachelard trazem reflexões importantes a respeito da criança e da infância mostrando a necessidade de olharmos essa fase preciosa da vida - a infância - da forma mais genuína possível, fornecendo os melhores espaços e condições para que a criança devaneie, imagine e modifique o mundo ao seu redor, independentemente da sua classe ou condição social.

Walter Benjamin alerta o adulto para não deixar que sua experiência silencie e reprima a criança que existe dentro de si, nem a criança que está se formando ali ao seu lado. Com uma visão marxista sobre consciência de classe e a necessidade de não deixar as crianças de lado nessa luta, ele traz, para o âmbito educacional e social da criança, uma possibilidade de revolução e de compreensão da sua própria classe social a fim de que possa entender a sua importância e valor e, assim, aprender a lutar por ela. $\mathrm{O}$ autor nos convida a valorizar e vivenciar melhor a experiência e as lições passadas pelos mais velhos, deixando de olhar somente para o agora. Modificar essa estrutura, através das crianças, pode reverter, futuramente, o enfraquecimento cultural que o nosso mundo vive hoje. Ainda sobre as crianças, ele nos ensina a valorizar e estimular os gostos e escolhas dos mais jovens para que, assim, possam desenvolver aquilo que dará mais certo na vida de cada um deles, no futuro.

Bachelard valoriza a infância que permanece em nós e é objeto para nossas possibilidades de mudar o mundo e saber sempre recomeçar. A criança enxerga o mundo de forma bela, em cores verdadeiras e sonha sem limites, por isso, a importância de valorizar seus pensamentos, vontades e devaneios. É preciso dar espaço para a imaginação e a criação de memórias vívidas. Sobre a educação, o autor nos deixa os ensinamentos da "Pedagogia do Não", que vai contra qualquer modelo de educação pronta, como as verdades absolutas, a superioridade dos pais e professores, a desvalorização do erro e, até mesmo, a utilização exacerbada de livros, apostilas e manuais de saberes fixos.

Nas teorias de Freud e Jung, encontram-se correlações importantes entre Benjamin e Bachelard e também outras contribuições que a Psicologia e a Psicanálise podem trazer à infância e à educação. Freud nos alerta sobre o peso da figura dos pais e demais adultos na formação do Eu (Ego) das crianças, principalmente no que diz respeito ao sentimento de culpa e censura internalizada, enquanto Jung nos traz a valorização dos sonhos e dos conteúdos latentes dos mesmos retomando a atenção ao que já foi citado anteriormente por Benjamin e Bachelard: a errônea desvalorização que o adulto faz dos pensamentos e das ideias das crianças. As crianças já possuem, em suas almas, os seus respectivos destinos cruzados, cabendo, portanto, ao adulto dar a mão a essa criança e ajudá-la a percorrer o seu próprio e não decidir ou modificar o seu percurso. 


\section{Referências}

ABBAGNANO, N. Dicionário de filosofia. Tradução de Alfredo Bolsi e Ivone Castilho Benedetti. 5 ed. São Paulo: Martins Fontes, 2007

AGATHON, M. et al. Dicionário Enciclopédico de Psicologia. Tradução de Hélder Viçoso. Lisboa: Textos \& Grafia, 2008.

BACHELARD, G. A poética do espaço. Tradução de Joaquim José Moura Ramos. São Paulo: Abril Cultural, 1978, p.180-354 (Coleção os Pensadores).

Fontes, 1988.

A poética do devaneio. Tradução de Antônio de Pádua Danesi. São Paulo: Martins

\section{4.}

O direito de sonhar. Tradução de José Américo Motta Pessanha. Rio de Janeiro: Beltrand,

BENJAMIN, W. Reflexões: a criança, o brinquedo, a educação. Tradução de Marcos Viníciius Mazzari. São Paulo: Summus, 1984.

Experiência e pobreza. In Obras escolhidas, Vol. 1. Magia e técnica, arte e política. São Paulo. Tradução de Sérgio Paulo Rouanet. Brasiliense, 1985, p.114-119. 1987.

Rua de mão única. Tradução de José Carlos Matins Barbosa. São Paulo: Brasiliense, Nau, 2015.

A hora das crianças: narrativas radiofônicas. Tradução de Aldo Medeiros. Rio de Janeiro:

BRANQUINHO, J., MURCHO, D. \& GOMES, N. Enciclopédia de termos lógico-filosóficos. São Paulo: Martins Fontes, 2005

FILLOUX, J. C. O inconsciente. Tradução de Norma Descaves. 2. ed. São Paulo: Difusão Europeia do Livro, 1966.

FRANZ, M. L. O processo de individuação In JUNG, C. G. O homem e seus símbolos $9^{a}$ Ed. Rio de Janeiro: Editora Nova Fronteira, 1977. 158-229

FREUD, S. O Mal Estar da Civilização. Tradução de Paulo César Lima de Souza. $6^{a}$ ed. São Paulo: Companhia das Letras, 2010

GALVÃO, G. G \& SILVA, L.B.O. Visita à Fábrica de Latão - Educação e denúncia. 2016.

HILLMAN, J. O código do ser. Tradução de Adalgisa Campos da Silva. Rio de Janeiro: Editora Objetiva, 1997.

JEAN, G. Bachelard, la infância e y la pedagogía. Cidade do México: Fondo de Cultura Económica, 1989

JUNG. C. G. O Homem e seus Símbolos. 9 Ed. Rio de Janeiro: Editora Nova Fronteira, 1977 O Homem à descoberta de sua alma. 2 ed. Porto: Livraria Tavares Martins, 1975

MARTÍNEZ, Albertina Mitjáns. O que pode fazer o psicólogo na escola? Revista Em Aberto, Brasília, v. 23, n. 83, p. 39-56, 2010. Disponível em: $<$ http:// files.psicologiafaev.webnode.com/200000057182da1a20f/O\%20QUE\%20PODE $\% 20 \mathrm{~F}$ AZER\%20UM\%20PSI\%20ESCOLAR.pdf>. Acesso em 05/05/2018. 
MORA, J. F. Dicionário de Filosofia. Traduzido por Antônio José Massano e Manuel Palmeirim. Lisboa: Dom Quixote, 1978

MOROSINI, M. C. Enciclopédia de Pedagogia Universitária vol 2. Brasília: INEP/MEC, 2006.

MARQUES, R. Dicionário breve de pedagogia. $2^{\mathrm{a}}$ edição. 2000. Retirado de http://www.eses.pt/usr/ramiro/docs/etica_pedagogia/dicionario\%20pedagogia.pdf em $03 / 12 / 2018$

OLIVEIRA, Cynthia Bisinoto Evangelista de.; MARINHO-ARAÚJO, Claisy Maria. (2009). Psicologia escolar: cenários atuais. Estudos e Pesquisas em Psicologia. Disponível em: $<$ http://www.e-publicacoes.uerj.br/index.php/revispsi/article/view/9075/7475>. Acesso em 05/05/2018.

RICHTER, Sandra. Bachelard e a experiência poética como dimensão educativa da arte. Revista Educação da UFSM, Vol 31, $\mathrm{N}^{\circ}$ 02, 2006. Disponível em: $<$ https://periodicos.ufsm.br/reveducacao/article/view/1541>. Acesso em 05/05/2018.

ROUDINESCO, E. \& PLOM, M. Dicionário de Psicanálise. Tradução de Vera Ribeiro e Lucy Magalhães. Rio de Janeiro: Zahar, 1998.

SANTOS, Sandro Vinícius Sales dos. (2015). Walter Benjamin e a experiência infantil: contribuições para a educação infantil. Pró-Posições, v. 26, n. 2, p. 223-239. Disponível em: <http://www.scielo.br/pdf/pp/v26n2/0103-7307-pp-26-02-0223.pdf>. Acesso em 05/05/2018. 